Original Article

\title{
Comparison of the Operative Time and Post-Operative Pain with Peek Cage versus Autologous Iliac Crest Bone Graft in Anterior Cervical Discectomy and Fusion
}

\section{Syed Ahmad Faizan, Syed Ahmad Bilal}

Department of Neurosurgery, Punjab Institute of Neurosciences (PINS), Lahore General Hospital (LGH), Lahore, Pakistan

\section{ABSTRACT}

Objective: The aim of this study was to compare the operative time and post-operative pain with PEEK cage method versus autologous iliac crest bone graft in anterior cervical discectomy and fusion in the cervical spine.

Material \& Methods: This was randomized control trial study (RCT). 90 patients with cervical disc disease, cervical stenosis with or without myelopathy and cervical trauma (fractures or facet jumps with disrupted disc) were included in the study from the Department of Neurosurgery, LGH, PINS, Lahore. Patients were evaluated with plain X-rays and MRI scans of the cervical spine. All patients underwent anterior cervical decompression and fusion. In 45 patients (group A), cervical fusion was achieved with PEEK cage method and in other 45 patients (group B), autologous Iliac Crest Bone graft was used.

Results: Mean age in group A was 57.1 years and in group B, it was 54.7 years. In group A, 31.1\% patients were of cervical disc disease, $28.8 \%$ of cervical degenerative stenosis and $40 \%$ were of cervical trauma. In group B, 15 patients $33.3 \%$ were of cervical disc disease, $24.4 \%$ of cervical degenerative stenosis and $42.2 \%$ were of cervical trauma. The mean Postoperative Visual Analogue Scale (VAS) score for pain was 2.8 in group A and 5.4 in group B patients.

Conclusion: The patients of group A (PEEK cage method) could be easily mobilized within bed and out of bed depending upon their neurological status. Decreased operative time and less post-operative pain makes PEEK cage method superior to autologous iliac crest bone graft in anterior cervical decompression and fusion.

Keywords: cervical disc disease, cervical spondylo-myelopathy, cervical facet jump, Anterior Cervical Decompression and Fusion (ACDF), PEEK (Polyetheretherketone) cage.

Corresponding Author: Syed Ahmad Faizan Bukhari Department of Neurosurgery, Punjab institute of Neurosciences/Lahore General Hospital, Lahore, Pakistan Email: drfaizan122@hotmail.com
Date of Submission: 10-02-2021

Date of Revision: 23-02-2021

Date of Online Publishing: 26-03-2021

Date of Print: 31-03-2021 


\section{INTRODUCTION}

The vast majority of patients with symptomatic cervical disc degeneration (CDD) showed good response to conservative treatment. ${ }^{1}$ In USA, the surgical incidence for CDD ranges between 5 and 60 per 100000 cases. $^{2}$ The gold standard for degenerative cervical spine diseases is Anterior Cervical Discectomy and Fusion (ACDF). ${ }^{3}$ But donor site morbidity, post-operative pain, long operative time and graft collapse or breakage are the complications for which an interest is growing to use artificial cages made of various materials, including polyetheretherketone (PEEK), and thus to replace the Autologous Iliac Crest Graft (AICG). ${ }^{4,5}$ However, there is no difference in neurological outcome with both bone graft and PEEK cage. ${ }^{6}$ Zhou et al. showed that the operative time with PEEK cages was much less than in autologous iliac crest graft, while no statistical difference was observed in improvement of pain in these groups. ${ }^{7}$ In another study of 41 patients, PEEK cages were inserted in 23 (56.10\%) while, the autologous iliac crest bone graft inserted in 18 (43.90\%). Operative time was $152 \pm 31.5$ minutes and no pain were reported in PEEK cage group, while in autologous iliac crest bone graft was $225.3 \pm 30.4$ minutes, and mild pain in 10 (55.5\%) patients, moderate in 6 (33.3\%) patients, while $2(11.2 \%)$ patients felt severe pain in the autologous iliac crest bone graft group, ${ }^{8}$ whereas, the operative time calculated by Lemcke et al. was 285 min in iliac bone graft. ${ }^{11}$ Skeppholm and Olered compared the pain intensity in group of autologous iliac crest bone graft group with and without bone graft; pain in graft group was higher $(33.3 \%)$ than in without bone graft group (13.3\%). ${ }^{9}$ In 2021, Ralph evaluated ACDF (Anterior Cervical Decompression and Fusion) using bone graft with plate fixation vs. without plate fixation and found that VAS scores was insignificantly different between the two groups. Pain improved after surgery from a verbal analogue score (VAS) of 7.9 to 1.5 in the plated-group, the mean improvement being $6.5 \pm 2.1$ (in a range of $1-9$ ), while in the Non-Plated group, pain also improved from 7.8 to 2.2 on average, the mean improvement being $5.6 \pm 2.8$ out of a total from $0-10 .^{10}$ Faldini et al. described that the preoperative mean pain of the PEEK cage group (VAS) was 7.0 (range 4 - 10); postoperative VAS was 3.0 (range $0-5$ ). ${ }^{12}$ Bjarne et al. evaluated the clinical outcome of 257 patients undergoing surgery using bone graft versus PEEK cage and concluded that there was no significant difference in pain relief for both the method but the trend towards functional improvement (operative time and post-operative pain) were high in autologous iliac crest bone graft then PEEK cage $(46.0 \%$ vs. $19.7 \%) .{ }^{1}$ It is therefore, imperative that a good understanding of the bio-mechanics of the implant and the cervical spine is achieved in order to select the appropriate implant for cervical spine surgery. PEEK cage is polyetheretherketone, a semi-crystal poly aromatic linear polymer and is designed to provide stability during spinal fusion which involves joining of two adjacent vertebrae. These PEEK cages eliminate need of a plate. As the cage is easy to implant, surgery time and traction on esophagus is significantly reduced. ${ }^{11}$ Therefore, the present study was designed to compare the two methods for cervical disc degeneration surgery.

\section{MATERIAL AND METHODS}

\section{Study Design \& Setting}

Randomized control trial (RCT). Total 90 patients with cervical disc disease, cervical stenosis or cervical trauma were included in the study and were operated with Anterior Cervical Discectomy and Fusion (ACDF) at Neurosurgery, Lahore General Hospital (LGH)/ Punjab Institute of Neurosciences (PINS) from January 2017 to December 2018. 


\section{Inclusion Criteria}

Those patients were included in whom the symptomatic cervical disc disease was not responsive to conservative management, cervical trauma (sub axial vertebral body fracture or unilateral/bilateral facet jumps with disrupted disc) and secondary cervical myelopathy that are compressible with ACDF.

\section{Exclusion Criteria}

Cervical neoplasm or radiotherapy of neck, ongoing cervical infection, previous neck surgery, pathology involving $\mathrm{C} 1, \mathrm{C} 2$ level of the cervical spine and disease involving two or more than two levels of cervical cord, were excluded.

\section{Clinical Assessment \& Data Collection}

A non-probability consecutive sampling technique was used to include all those patients that met the inclusion criteria. In 45 patients (group A), cervical fusion was achieved with PEEK cage method and in other 45 patients (group B), autologous Iliac Crest Bone graft was used. Patients were evaluated for neurological status and this data was documented. All patients were evaluated preoperatively with $\mathrm{X}$-rays and MRI scans of the cervical spine. Patients were randomly grouped by lottery method for PEEK cage (Group A) or grouped for conventional autologous bone graft. (Group B).

All patients were explained in detail about their procedure and informed consent were taken. In all patients of both groups, anterior cervical discectomy was done in the same way and end plates of vertebral bodies were prepared for fusion. In group A patients, the cervical interbody fusion was achieved using PEEK (polyetheretherketone) cage and in group B patients, the purpose was achieved using conventional autologous iliac crest bone graft.

Postoperatively, all patients were assessed and documented for operative time (in minutes) as reported in the anesthesia and operative notes. They were also documented for severity of postoperative surgical site pain according to Visual Analogue Scale (VAS).

\section{Polyetheretherketone (PEEK) Cage}

This procedure was done in the supine position. After giving general anesthesia, aseptic measures were taken. Linear incision was made at the right side of neck in a skin crease over involved vertebra. Platysma was cut. Spine was approached, keeping sternocleidomastoid and carotid on lateral aspect and trachea and esophagus on the medial aspect. Involved level is confirmed under the $\mathrm{C}$ - arm image. Longus coli muscle was split. Involved disc was removed. Thecal decompression was confirmed. End plates were prepared. Bone pieces which were taken during the removal of osteophytes were placed in peek cages of appropriate size. The cage was placed in the disc space and snugly fittea. Adjacent vertebrae were fixed with plates. Wound was closed and post-operative X-rays were taken.

\section{Statistical Analyses}

Chi-square test and t-test (independent samples) to investigate the relative significance or significant difference between the mentioned groups.

\section{RESULTS}

\section{Gender Distribution}

In group A, 31 (68.8\%) were males and 14 (32.2\%) were females whereas in group B, 28 (62.2\%) were males and 17 (37.8\%) were females (Table 1).

\section{Age Range}

Mean age of the patients in group $A$ was 57.1 years (Range $=20-77$ years) and in group $B$, it was 54.7 years $($ Range $=18-74$ years $)($ Table 1$)$.

Pak. J. of Neurol. Surg. $-2021-25$ (1): 76-82. 


\section{Clinical Presentation}

In group $A$, out of 45 patients, 14 patients (31.1\%) were of cervical disc disease, 13 (28.8\%) of cervical degenerative stenosis and 18 (40\%) were of cervical trauma. In group B, out of 45 patients, 15 patients (33.3\%) were of cervical disc disease, $11(24.4 \%)$ of cervical degenerative stenosis and 19 (42.2\%) were of cervical trauma (Table 1). Figures $1(\mathrm{a})$ and $1(\mathrm{~b})$ showing lateral views of the cervical spine on X-rays and MRI (T2). Figure 1(c) shows the $X$-rays of cervical spine in AP and lateral views post operatively.

\section{PEEK Cage vs. Iliac Crest Bone Graft Operative Time}

Mean operative time in group A patients was 73 min (range $=60-90$ min). In group B patients, mean operative time was $92 \mathrm{~min}$ (75- $120 \mathrm{~min}$ ).

\section{Postoperative Surgical Site Pain}

The mean Postoperative Visual Analogue Scale (VAS) scores for pain was 2.8 (range $=2$ to 4 ) in group $A$ and 5.4 (range $=4-7$ ) in group $B$ patients. Therefore, patients of group $A$ could be easily mobilized within bed and out of bed depending upon their neurological status.

\section{The t-test Evaluations}

A significant difference ( $p$ value: $<0.0001$ ) existed between the mean scores of post-operative VAS in groups $A$ and $B$.

\begin{tabular}{|c|c|c|c|}
\hline Parameters & $\begin{array}{l}\text { Group A } \\
\text { (PEEK Cage) }\end{array}$ & $\begin{array}{l}\text { Group B } \\
\text { (Autologous Bone Graft) }\end{array}$ & $\begin{array}{l}\text { Chi Square/ } \\
\text { T test \& p Value }\end{array}$ \\
\hline \multicolumn{4}{|l|}{ Gender } \\
\hline Male & $\mathrm{n}=31(68.8 \%)$ & $n=28(62.2 \%)$ & $\chi^{2}=0.4429 ; p$ value: 0.505 \\
\hline Female & $n=14(32.2 \%)$ & $\mathrm{n}=17(37.8 \%)$ & \\
\hline Mean Age (Years) & $57.1($ Range $=20-77$ years $)$ & $54.7($ Range $=18-74$ years $)$ & \\
\hline \multicolumn{4}{|l|}{ Pathology } \\
\hline Cervical Disc & $\mathrm{n}=14(31.1 \%)$ & $\mathrm{n}=15(33.3 \%)$ & \\
\hline Cervical Stenosis & $\mathrm{n}=13(28.8 \%)$ & $\mathrm{n}=11(24.4 \%)$ & $\chi^{2}=0.2282 ; p$ value: 0.8927 \\
\hline Cervical Trauma & $\mathrm{n}=18(40 \%)$ & $\mathrm{n}=19(42.2 \%)$ & \\
\hline Mean Operative Time (Minutes) & 73 (Range $=60-90 \mathrm{~min})$ & $92 \min (75-120 \mathrm{~min})$ & - \\
\hline & & & $\mathrm{T}$ test: $48.37 ; \mathrm{df}=88$ \\
\hline $\begin{array}{l}\text { Mean Post-Operative Pain } \\
\text { (VAS = Visual Analogue Score) }\end{array}$ & $2.8 \pm 0.2($ Range $=2-4)$ & $5.4 \pm 0.3($ Range $=4-7)$ & $\begin{array}{l}\mathrm{Cl}(95 \%)=-2.707 \text { to }-2.493 \\
\mathrm{P} \text { value }<0.0001^{*} \\
\text { *Highly significant }\end{array}$ \\
\hline
\end{tabular}




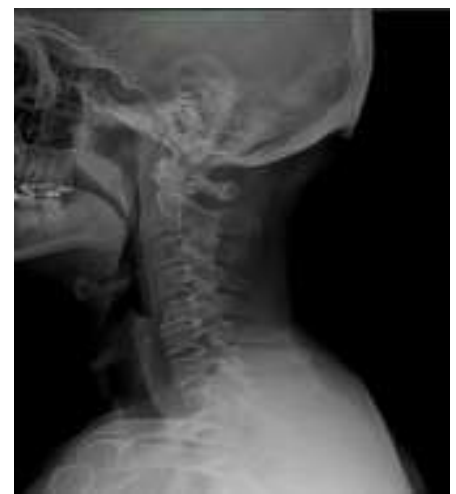

(a)

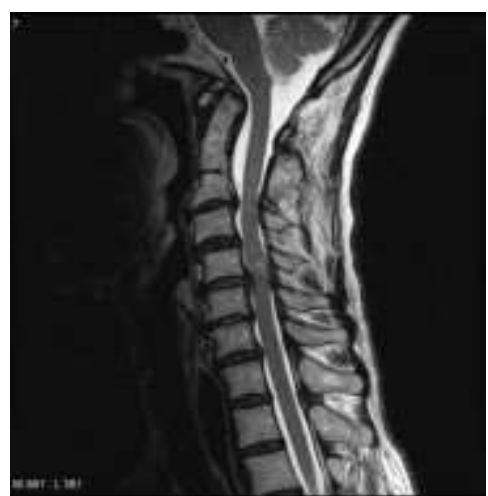

(b)

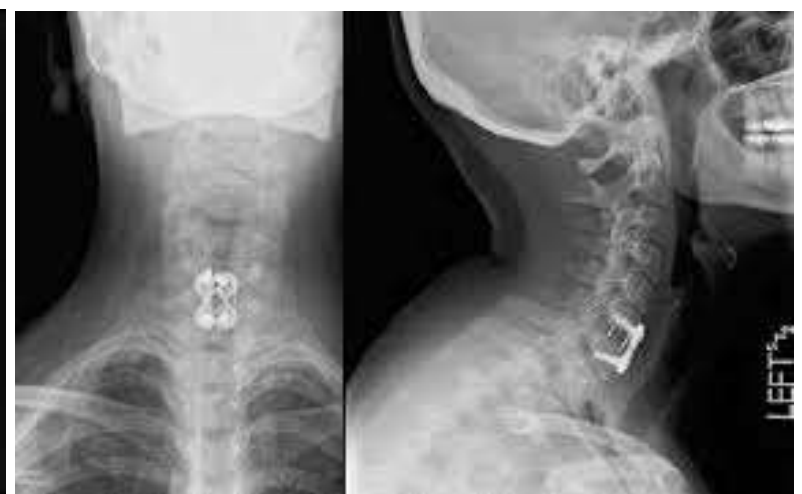

(c)

Figure 1: (a) Preoperative X-ray showing cervical spondylosis C5-6 (b) preoperative MRI sagittal view showing C5-6 disc prolapse (c) postoperative X-ray showing PEEK cage in situ.

\section{DISCUSSION}

The surgical treatment of cervical pathologies who failed to respond to conservative treatment have always been an area of interest among spine surgeons. Anterior Cervical Discectomy and Fusion (ACDF) is a time tested procedure and well documented for its short term as well as long term results in relieving radicular pain in cervical disc disease and cervical stenosis. ${ }^{4,13-15}$ ACDF has also been used in trauma patients where intervertebral disc is disrupted along with fracture or subluxation. ${ }^{17,18}$ Conventionally, autologous bone graft has been used for fusion between end plates of vertebral bodies and is secured with a buttress of anterior plate. Most commonly, the graft is harvested from iliac crest. This autologous iliac crest bone grafting is associated with donor site morbidities including an additional surgical procedure, significant postoperative bone pain, surgical site infection and delayed postoperative mobilization.

In both groups, most of the patients (40 $42 \%)$ were found with cervical trauma. In the current study, the mean Postoperative Visual Analogue Scale (VAS) score for pain was 2.8 in group A (PEEK Cage) and 5.4 in group $B$ patients (Iliac Crest Bone Graft). Therefore, patients of group A could be easily mobilized within bed and out of bed depending upon their neurological status. The mean operative time in group $A$ patients (73 minutes) was lower than the group B patients (92 minutes).

In our study, in the two study groups with significant difference ( $p$ value $<0.0001$ ) in VAS postoperatively (2.8 versus 5.4). Group A which used PEEK cage showed greater pain reduction making an early recovery in the patients than group B where Autologous Bone Graft was used. In another study by $\mathrm{Yu}$-Cheng Chou et $\mathrm{al}^{19}{ }^{19}$ a comparative analysis of autogenous and peek grafts showed no significant benefit in using either PEEK or autogenous grafts. $\mathrm{Ni}$ et al favored the use of peek grafts followed by use of autografts in the adjacent spine in long fusion surgeries in the lumbar region. ${ }^{20}$

Several attempts have been made for advent of different cages for improvement in biomechanical stability as well as trying to decrease the donor site morbidities by decreasing the amount of harvested bone graft. Polyetheretherketone (PEEK) cage is a recent advancement in this regard. It serves both of the above mentioned purposes well. It does not need any iliac crest bone grafting thus reducing the morbidity as well as operative time. Studies have shown that the efficiency of both procedures in improving the Radicular pain has been statistically similar. Our Study shows that the PEEK cages are better in terms of Postoperative surgical time and operative time. 


\section{CONCLUSION \& RECOMMENDATION}

PEEK cage method is a newer treatment modality for the anterior cervical fusion in our country and has advantages of decreased operative time and less postoperative time over conventional method of using autologous iliac crest bone graft. A long term follow ups are still required in this regard.

\section{Limitations}

This was a single centered study with limited sample size. More cases from multi-center studies could be added for the affirmation of the reported outcome.

\section{REFERENCES}

1. Bjarne L, Paal AR, Sundseth J, Helseth E. Anterior cervical discectomy with fusion in patients with cervical disc degeneration: a prospective outcome study of 258 patients (181 fused with autologous bone graft and 77 fused with a PEEK cage). BMC Surgery, 2010; 10: 10.

2. M. A. Pfallerand D. J. Diekema. Epidemiology of Invasive Candidiasis: a Persistent Public Health Problem. Clin. Microbiol Rev, 2007; 20 (1): 133163.

3. Korinth MC. Treatment of cervical degenerative disc disease: current status and trends. Zentralbl Neurochir. 2008; 69: 113-124.

4. Peolsson A: Investigation of clinically important benefit of anterior cervical decompression and fusion. Eur Spine J. 2007; 16: 507-514.

5. Fernandez-Fairen M, Sala P, Dufoo M Jr, Ballester J, Murcia A, Merzthal L. Anterior cervical fusion with tantalum implant: a prospective randomized controlled study. Spine, 2008; 33: 465-472.

6. Chi-Chien N, Jen-Chung, Chen L, Chen W-J, et al. Outcomes of Interbody Fusion Cages Used in 1 and 2-levels Anterior Cervical Discectomy and Fusion: Titanium Cages Versus Polyetheretherketone (PEEK) Cages. Journal of Spinal Disorders \& Techniques, 2010; 23 (5): 310316.

7. Z. Jian, X. Qing, D. Jian, L. Xilei, Z. Xiaogang, F. Taolin, L. Hong. Comparison of standalone polyetheretherketone cages and iliac crest autografts for the treatment of cervical degenerative disc diseases. Acta Neurochir (Wien). 2011; 153 (1): 115-22.

8. Hossam IM, Islam AF. Anterior Cervical Fusion of Single Level Cervical Disc Disease A Retrospective Analysis of Outcome. E.J.N.S. 2010; 25 (2): 95-112.

9. Skeppholm M, Olerud C. Pain from donor site after anterior cervical fusion with bone graft: a prospective randomized study with 12 months of follow-up. European Spine Journal, 2013; 22 (1): 142-147.

10. Ralph JM, MT. C. Anthony and D. Deniz. Biphasic Calcium Phosphate Contained within a Polyetheretherketone Cage with and without Plating for Anterior Cervical Discectomy and Fusion. Orthopaedic Surgery, 2012; 4 (3): 156-165.

11. Lemcke $J$, Al-Zain $M$, Meier $U$, Suess $O$. Polyetheretherketone (PEEK) Spacers for Anterior Cervical Fusion: A Retrospective Comparative Effectiveness Clinical Trial. Open Orthop J, 2011; 5: 348-353.

12. Faldini C, Chehrassan $M$, Miscione MT, Acri $F$, d'Amato $M$, Pungetti $C$, Luciani D, Giannini S. Single-level anterior cervical discectomy and interbody fusion using PEEK anatomical cervical cage and allograft bone. J Orthop Traumatol, 2011; 12 (4): 201-205.

13. Hacker RJ, Cauthen JC, Gilbert TJ, Griffith SL: A prospective randomized multicenter clinical evaluation of an anterior cervical fusion cage. Spine, 2000; 25: 2646-2654.

14. Goldberg EJ, Singh K, Van U, Garretson R, An HS: Comparing outcomes of anterior cervical discectomy and fusion in workman's versus nonworkman's compensation population. Spine J, 2002; 2: 408-414.

15. Gore DR, Sepic SB, Anterior discectomy and fusion for painful cervical disc disease. A report of 50 patients with an average follow-up of 21 years. Spine, 1998; 23: 2047-2051.

16. Jagannathan J, Shaffrey $\mathrm{Cl}$, Oskouian RJ, Dumont AS, Herrold C, Sansur CA, et al. Radiographic and clinical outcomes following single-level anterior cervical discectomy and allograft fusion without plate placement or cervical collar. J Neurosurg Spine, 2008; 8: 420-428.

17. Jain V, Madan A, Thakur M, Thakur A. Functional Outcomes of Subaxial Spine Injuries Managed 
With 2-Level Anterior Cervical Corpectomy and Fusion: A Prospective Study. Neurospine, 2018; 15 (4): 368-375.

18. Madan A, Thakur M, Sud S, Jain V, Singh Thakur RP, Negi V. Subaxial Cervical Spine Injuries: Outcomes after Anterior Corpectomy and Instrumentation. Asian J Neurosurg. 2019; 14 (3): 843-847.

19. Yu-Cheng Chou, Der-Cherng DC, Hsieh WA, Cchen WF, Yen PS, Harnod T, et al. Efficacy of anterior cervical fusion: comparison of titanium cages, polyetheretherketone (PEEK) cafes and autogenous bone grafts. Journal of Neurosciences. 2008; 15 (11): 1240-1245.

20. Ni J, Zhenf $Y$, Liu N, Wang $X$, Fang $X$, Phukan $R$, Wood KB. Radiological evaluation of anterior lumbar fusion using PEEK cages with adjacent vertebral autograft in spinal deformity long fusion surgeries. Eur. Spine Journal, 2015; 24 (4): 791-799.

\section{Additional Information}

Disclosures: Authors report no conflict of interest.

Ethical Review Board Approval: The study was conformed to the ethical review board requirements.

Human Subjects: Consent was obtained by all patients/participants in this study.

Conflicts of Interest:

In compliance with the ICMJE uniform disclosure form, all authors declare the following:

Financial Relationships: All authors have declared that they have no financial relationships at present or within the previous three years with any organizations that might have an interest in the submitted work.

Other Relationships: All authors have declared that there are no other relationships or activities that could appear to have influenced the submitted work.

\section{AUTHORS CONTRIBUTIONS}

\begin{tabular}{|l|l|l|}
\hline Sr.\# & Author's Full Name & Intellectual Contribution to Paper in Terms of: \\
\hline 1. & Syed Ahmad Faizan & Study design, methodology, data Collection and referencing. \\
\hline 2. & Syed Ahmad Bilal & Data calculations and analysis. Paper writing. \\
\hline
\end{tabular}

